\title{
Research on the construction of carbon emission model of power generation industry in Jilin province
}

\author{
Weiwei Jiang ${ }^{1, *}$, Zhiyu Song ${ }^{1}$, Zhongyan Wang ${ }^{1}$, and Ping Guo ${ }^{2}$ \\ ${ }^{1}$ Jilin Province Electric Power Science Research Institute Co, Ltd, Changchun, Jilin, China \\ ${ }^{2}$ Jilin University, Changchun, Jilin, China
}

\begin{abstract}
Although Jilin Province has abundant forest reserves and has a relatively large carbon neutral advantage compared to other provinces, the installed capacity of thermal power is still relatively high, and the installed capacity of renewable energy such as wind power, photovoltaic and hydropower is insufficient. This paper builds a carbon emission model for the power generation industry in Jilin Province based on the characteristics of the power generation industry in Jilin Province and years of field test experience.
\end{abstract}

\section{Introduction}

On the basis of the "Paris Agreement", China has pledged that carbon dioxide emissions will peak by 2030 and be carbon neutral by 2060. China's power industry carbon emission indicator (unit power supply carbon emissions $\mathrm{gCO}_{2} / \mathrm{kW} \cdot \mathrm{h}$ ) has dropped from about 900 grams in 2005 to about 600 grams in 2019 (a decrease of about 30\%), but it is still higher than the global average of 450 grams Out $30 \%$, The task for China to achieve its goals is very arduous [1].

Although Jilin Province has abundant forest reserves and has a relatively large carbon neutral advantage compared to other provinces, the installed capacity of thermal power is still relatively high, and the installed capacity of renewable energy such as wind power, photovoltaic and hydropower is insufficient [2-3]. Fig.1 shows the proportion of electricity installed capacity in Jilin Province in 2020.

This paper builds a carbon emission model for the power generation industry in Jilin Province based on the characteristics of the power generation industry in Jilin Province and years of field test experience.

\section{Model construction of coal-fired power plant}

Internationally, the calculation of carbon emissions from coal-fired power generation is divided into two categories. One is to directly collect flue gas $\mathrm{CO}_{2}$ emissions through online

\footnotetext{
*Corresponding author: weiwei jiang1990@163.com
} 
monitoring methods; the other is to calculate based on fuel input, which is the main method for calculating $\mathrm{CO}_{2}$ emissions from coal-fired power generation.

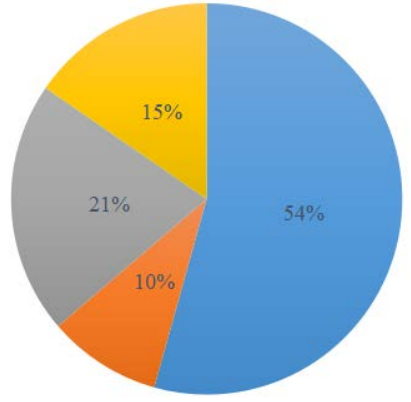

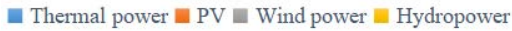

Fig.1. Proportion of installed power capacity in Jilin Province in 2020.

Coal mining, water washing and other links before coal-fired power generation belong to the coal mine's carbon emissions calculations. The carbon emission process of coal-fired power generation includes transportation, combustion, auxiliary machinery, desulfurization, denitrification, and dust removal. The model is as follows.

$$
E_{\text {Total }}=E_{\text {Auxiliary equipment }}+E_{\text {Combustion }}+E_{\text {Desulfurization }}+E_{\text {Denitrification }}+E_{\text {Dust collector }}+E_{\text {Maintenance }}
$$

In the formula, $E_{\text {Total }}$ is the total $\mathrm{CO}_{2}$ emissions of coal-fired power plants, and $E_{\text {Auxiliary equipment }}$ refers to the indirect $\mathrm{CO}_{2}$ emissions of the auxiliary power consumption of the auxiliary equipment in the boiler combustion, which is related to the calculation of the auxiliary power consumption. $E_{\text {Combustion }}$ refers to the $\mathrm{CO}_{2}$ emissions generated by the chemical combustion process of coal, $E_{\text {Desulfurization }}$ is the $\mathrm{CO}_{2}$ emissions generated by the flue gas desulfurization process, $E_{\text {Denitrification }}$ is the $\mathrm{CO}_{2}$ emissions generated by the denitration process, $E_{\text {Dust collector }}$ is the $\mathrm{CO}_{2}$ emissions generated by the dust removal process, $E_{\text {Maintenance }}$ is the amount of $\mathrm{CO}_{2}$ emissions from the process of maintaining equipment in a power plant.

The major foreign economies mainly adopt the 2006 edition of the Intergovernmental Panel on Climate Change (IPCC) emission calculation guidelines for carbon emissions accounting; domestically issued the "2006 IPCC National Greenhouse Gas Inventory Guidelines", and the IPCC applies to carbon emission calculation standards for thermal power generation is as follows

$$
E_{(\mathrm{i}, \text { Carbon dioxide emissions })}=A D_{(i, \text { Fuel consumption })} \times E F_{(i, \text { Emission factor })} \times O_{(\text {Carbon oxidation rate })} \times \frac{44}{12}
$$

where $E_{\text {(i,Carbon dioxide emissions) }}$ is calculated by fuel type, i is fuel type, $A D_{(i, \text { Fuel consumption) }}$ is the amount of fuel burned, and $E F_{(i, \text { Emission factor })}$ is calculated by fuel type The given default emission factor, $O_{\text {(Carbon oxidation rate) }}$ is the oxidation rate of carbon element (greater than $98 \%)$.

The built model algorithms mainly include: material balance algorithm, emission coefficient method, energy model method, life cycle method and actual measurement method. The coal quantity and cost calculation errors of the above models are relatively large, and they lack initiative due to the influence of the coal market, and there are 
significant limitations in reducing carbon emissions from the coal type. This paper adopts a new calculation method for the peak carbon emission model before 2030 .

The main calculation idea of the model: According to the real-time data of the boiler's DCS, such as the main steam flow rate and the extraction steam parameters of each section, the boiler output heat is calculated in a positive balance, and the coal heat is calculated according to the boiler efficiency correction (less efficiency fluctuation) and the amount of coal entering the furnace Then calculate the total element carbon content of coal according to the big data Bayesian AI statistical method, and then calculate the carbon emissions. The overall calculation error is small, which is fully suitable for the carbon emission data model prediction of coal-fired units.

The Bayesian AI statistical algorithm is used to calculate the calorific value of coal and analyze the error. The carbon content of the coal entering the furnace is obtained according to the industrial analysis and type of coal production area statistics and the coal characteristics of the area. After analyzing the collected coal quality data from all over the country, comparing the calculated calorific value of coal with the laboratory calorific value to verify the applicability of the Bayesian AI statistical algorithm. According to the big data laboratory value of the Jilin Provincial Electric Power Research Institute on the province's coal quality data statistics, a data model of coal quality calorific value and all elements is established, which is used as the coal-burning carbon emission formula, as follows:

$$
\begin{aligned}
& C_{\mathrm{ar}}+H_{\mathrm{ar}}+O_{\mathrm{ar}}+N_{\mathrm{ar}}+S_{\mathrm{ar}}+A_{\mathrm{ar}}+M_{\mathrm{ar}}=100 \% \\
& C=\sum_{n} \sum_{k} I \times P \times E \times U \times f \\
& N_{d a f}=-0.50953+0.3297 H_{d a f} \\
& H_{d a f}=8.21833-0.05303 C_{d a f}
\end{aligned}
$$

In the formula: $C_{\mathrm{ar}}, H_{\mathrm{ar}}, O_{\mathrm{ar}}, N_{\mathrm{ar}}, S_{\mathrm{ar}}, A_{\mathrm{ar}}$ and $M_{\mathrm{ar}}$ respectively represent the mass fractions of carbon, hydrogen, oxygen, nitrogen, sulfur, ash and moisture in the fuel.

The calorific value of coal is obtained approximately using the results of elemental analysis, and the calculation method of calorific value is obtained through Bayesian statistics based on the big data test values of coal quality across the country:

$$
\mathrm{Q}_{\mathrm{dw}}^{\mathrm{y}}=K_{1} C_{a r}+K_{2} H_{a r}+62.85 S_{a r}-104.7 O_{a r}+2.09\left(100-A_{a r}-M_{a r}\right)\left(1-\frac{10 A_{a r}}{100-M_{a r}}-23 M_{a r}\right)
$$

In the formula: when coal $C_{\mathrm{ar}}>95 \%$ or $H_{\mathrm{ar}} \leq 1.5 \%, K_{1}=327, K_{1}=335$ for other coals; when $C_{\text {daf }}<77 \%, K_{2}=1256$, and $K_{2}=1298$ for other coals. According to the big data of coal quality in Jilin Province and the Bayesian AI statistical results of typical representative coal samples, the average value of the calculated calorific value and the calorific value of the test is $2.7 \%$, which is in line with the allowable error of the test.

A statistical analysis of the thermal efficiency of the boilers of various power plants found that the lower the calorific value of coal, the lower the thermal efficiency.

\section{Model construction of photovoltaics and wind power}

The installed capacity of renewable energies such as photovoltaics and wind power in Jilin Province is continuously increasing, and there is a phenomenon of "abandoning wind and light" on a large scale. Photovoltaic, wind power, and hydropower have high production 
costs, grid fluctuations, and poor peak-shaving capabilities. There is a lot of power waste during grid commissioning. This part of the carbon verification calculation of "abandoning wind and abandoning light" has not been reasonably incorporated into the carbon emission data model. For wind power generation, in order to ensure the reliability of dispatch, it will have a greater impact on the wind turbines. On the premise that the abandonment rate of wind power is less than $8 \%$, wind power generation is related to the wind speed during this period, which has great randomness and Volatility, the mathematical model is constructed based on the real-time power of wind power and climate data.

Renewable energy sources such as photovoltaics and wind power do not produce carbon emissions during the power generation process. They only generate carbon emissions in the production link of infrastructure equipment. They are allocated according to the 20-year production cycle of wind power and photovoltaics to construct a mathematical model of carbon emissions. For example, wind power production links: including the production emissions of wind farm equipment raw materials (generally including copper, steel, pig iron, aluminum, glass fiber, etc.) during infrastructure construction, transportation carbon emissions, construction carbon emissions, and vegetation damage on engineering land and installation land Carbon emission correction.

For hydropower projects in Jilin Province, carbon emissions research focuses on the later stage of the reservoir emissions and the carbon emission reduction evaluation of power generation during the operation period. The buildings themselves in the early stage of infrastructure construction and the calculation of carbon emissions generated during the construction period are critical and have an impact on the later stage of carbon emissions. Larger, the model is also constructed according to the wind power infrastructure and apportionment method. Fig. 2 and Fig.3 are the analysis charts of carbon emissions during the construction of wind power. Photovoltaic and hydropower are also constructed according to this model.

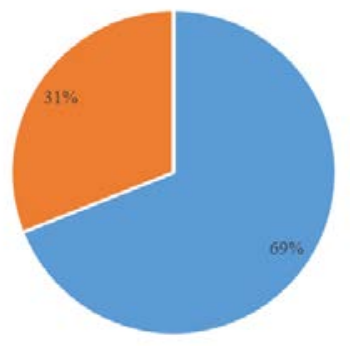

= Maintenance $=$ Vegetation carbon sink changes $=$ Operation

Fig. 2. Carbon emissions ( $\mathrm{t} \mathrm{CO} 2$ ) at each stage of wind power production.

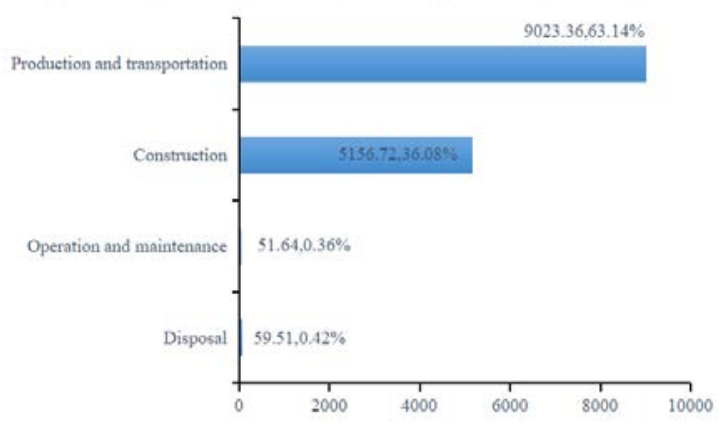

Fig. 3. Carbon emissions at various stages of wind power operation and maintenance. 
According to the above data model, the average carbon emission of wind power in Jilin Province is $7.0-10.8 \mathrm{~g} / \mathrm{kW} \cdot \mathrm{h}$, the average carbon emission of photovoltaic power is 10 $50 \mathrm{~g} / \mathrm{kW} \cdot \mathrm{h}$, and the average carbon emission of hydropower is $17-22 \mathrm{~g} / \mathrm{kW} \cdot \mathrm{h}$.

\section{Conclusions}

Based on the 13th Five-Year Plan and the 14th Five-Year Plan, this article builds model algorithms based on the growth of thermal power, wind power, photovoltaic and hydropower, and related energy-saving transformations. This project is based on the carbon emission test and test standards of coal-fired power generation, and builds an algorithm model of the unit power generation carbon emission index through the verification of test data, and then adds the power generation industries such as wind power, photovoltaic and hydropower to build the overall carbon emission index of the power generation industry in Jilin Province Algorithm model.

\section{References}

1. Wang Yaxian. Research on Carbon Emissions and Total Carbon Intensity Reduction of China's Thermal Power Industry[D]. North China Electric Power University (Beijing), 2020.

2. Dong Ruifeng, Chen Haojun, Cao Zhenqian, Wang Fengtao. Methods and comparison of carbon emission verification for coal-fired boilers[J]. Industrial Furnace, 2021, 43(02): 41-44

3. Cong Rijie, Han Jieping. Research on the Early Warning Evaluation of Carbon Emissions of Thermal Power Plants in my country Based on Artificial Neural Network--Taking a Thermal Power Plant in Jilin Province as an Example[J]. Ecological Economy, 2019, 35(10): 37-41. 